\title{
ورقة عمل
}

\section{"التغذية العلاجية بين الواقع و المأمول" \\ أ.د. اشرف عبد العزيز عبد المجيد}

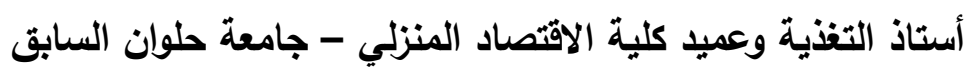
وعضو اللجنة الوطنية للتفذية علي مستوى ج.م.ع

علم الفلسفة عرف الواقع بانه حالة الأشياء كما هي موجودة، وكما وجدت حولنا. اما المأمول فهو الثيئ المنتظر الذي نتمنى حدوثة. أما التغذية العلاجية فهى أنظمة متبعة في التغذية التهاهية كى تحد من المضاعفات الناتجة من الامراض المختلفة Complications فالعلاج لا ينت

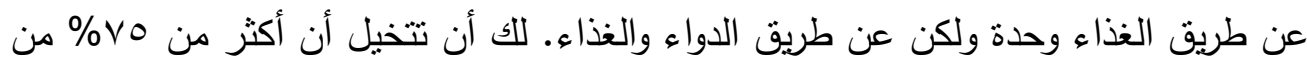

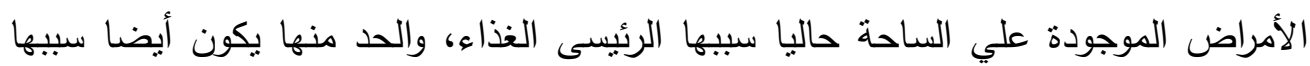
الغذاء.

من المنوط بالتغذية العلاجية: هو الثخص الدارس لمقررات التغذية بشكل عام ومقررات التغذية العلاجية بشكل خاصة. وللأسف نجد الأن علي الساحة العديد من المتحدثين بإسم التغذية ممن ليس لهم دخل بهذا التخصص الخطير (لانه يمس حياة الانسان). ولاهمية

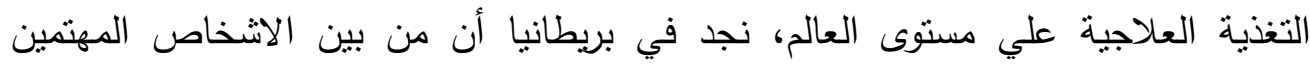

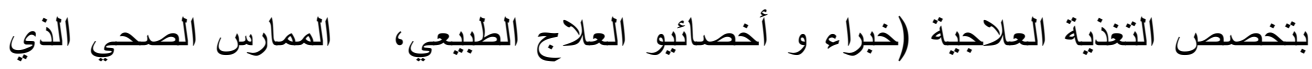
يسعى لتوسيع معرفته بأصول التغذية، العاملون في مجال الصحة و والتغذية التية الصحية؛ الأطباء، التمريض، معدي الطعام... إلخ، العاملون في ميدان الطب البديل، العاملون في في فئهن

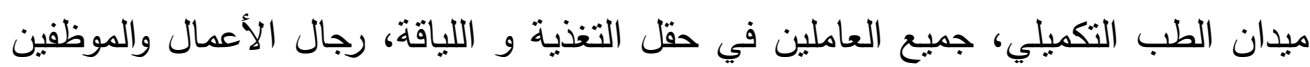
المعنيين بتجهيز وإنتاج الأغذية في مجال التسويق). 
يجب أن تكون المنظومة متكاملة من اجل الحصول علي شفاء المريض [ (فالطبيب

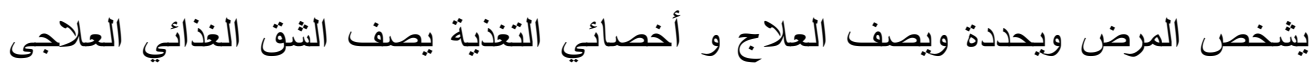

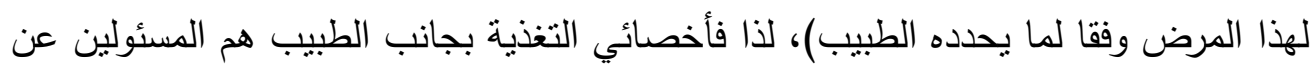

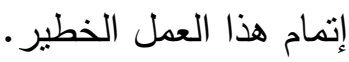

ولان كلية الاقتصاد المنزلي - جامعة حلوان رائدة في هذا المجال قد تم انشاء برنامج جديد باللغة الاتجليزية بنظام الساعات المعتمدة بمصروفات (التغذية العلاجية) هذا بالاضافة الي ما تخرجة الكلية من متخصصين في التغذية قادريين علي اتمام هذه العملية منذ قديم الزمن. وكان الهذف من برنامج التغذية العلاجية هو إعداد متخصص وخبير في التغذية

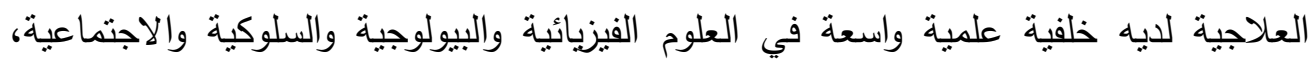
والاتصالات، جنبا إلى جنب مع المعرفة المتقدمة في مجالات الغذاء والتغذية في الصحة ومله ولهابه

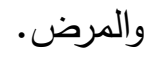

ولكي يكون الثخص المناسب في المكان المناسب، لابد وأن تبدى الدولة اهتماما كبير لاكتمال المنظومة الطبية السليمة، وأذكركم مرة أخري (فمنظومة التغذية العلاجية ما هي الا طبيب يشخص المرض ويحددة ويصف العلاج + أخصائي التخذية يصف الثق الغذائي العلاجى لهذا المرض). 